\section{Determinants of the conditioned suppressive properties of a stimulus}

\author{
THOMAS W. BAKER and MICHAEL LOUGEE* \\ Lawrence University, Appleton, Wis. 54911
}

Probability of signaled shock, shocks per total CS duration, contingency of CS and shock, as well as shock density were variables manipulated in a CER paradigm. Both contingency and shocks per total CS duration were found to influence the amount of suppression. Relationships between probability of signaled shock and CS duration were implicated and discussed.

Recent theorizing concerning the role of the $\mathrm{CS}$ in either avoidance learning or conditioned suppression has stressed different variables; e.g., (1) Herrnstein (1969) looks at the CS in terms of its signal value for periods of greater shock density; similarly, Bolles \& Grossen (1970) contend that CS termination signals a safe (shock-free) period; (2) Anger (1969), arguing in support of a two-factor interpretation of avoidance learning, maintains that the CS does become an aversive stimulus and that this aversiveness can be equated operationally with the number of shocks per total stimulus exposure time; (3) Bolles, Stokes, \& Younger (1966) and Lockard (1963) have presented similar positions, namely that, as the probability of CS-US contingency increases, the CS becomes more discriminative or informational. These latter two interpretations have been shown to be equivalent (Fleming \& Hershman, 1969). In addition, Rescorla (1968) has pointed out that the CS-US contingency (or probability of signaled shock) must be understood relative to non-CS-US contingencies present. The problem becomes one of teasing apart experimentally these nonorthogonal interpretations.

The present experiment attempts to assess the importance of three variables mentioned above: (1) shocks per total CS duration, (2) probability of signaled shock, and (3) the contingency relationship between CS and US.

\section{DESIGN}

A mixed design was employed. Each of three groups received two different schedules consisting of CS alone, CS + shock, and shock alone, which were presented sequentially in time. Within each group, the two schedules differed in the type of CS (noise and light), but the total CS duration, as well as the total duration of each schedule (CS + non-CS periods), was the same for all groups. Although the total CS duration was the same in all schedules,

* Now at the Department of Psychology. University of Massachusetts, Amherst, Mass. 01002 . the number and duration of each CS presentation was manipulated in order to provide different levels of probability of signaled shock and CS-US contingency. The non-CS periods of each schedule were characterized by differing numbers of shocks. This manipulation alters both the contingency relationship and overall shock density. A complete description of these manipulations is given below and summarized in Table 1. After each $S$ had received repeated exposure to the two schedules appropriate to its group, the $S$ was returned to the barpress situation, and tests for the amount of suppression occasioned by each CS were conducted.

\section{PROCEDURE}

The Ss consisted of 36 naive male albino rats (12 Wistar and 24 Sprague-Dawley origin), weighing $250-350 \mathrm{~g}$ at the beginning of the experiment and maintained thereafter at $80 \%$ of an ad lib food and water control group of the same age. Seven Ss were lost due to the apparatus failure or errors by $E$, leaving 9 Ss in Group 1, 12 in Group 2, and 8 in Group 3.

Initial barpress training was carried out in five Lehigh Valley single-bar nonsound-insulated automatically programmed operant chambers. All further training and testing was carried out in a Grason-Stadler operant chamber enclosed by a sound-insulated chest and located in a darkened sound-insulated room adjacent to the room housing the solid-state programmer.

The two CSs employed consisted of either a light (L) provided by the illumination of three jeweled (white, red, and green) 28-V lamps arranged horizontally on the front panel of the chamber. The auditory (N) CS was $68 \mathrm{~dB}$ of white noise provided by a Grason-Stadler noise generator (Model 455C). This represented an increase of $5 \mathrm{~dB}$ above background noise level $(63 \mathrm{~dB}$ without ventilation fan on), as measured by a General Radio sound level meter (Model $1551-\mathrm{C}, 20 \mathrm{KHz}$ setting). Pilot studies had demonstrated these CS intensities to yield equivalent amounts of suppression following CER training. Shocks to the chamber floor grid were provided by a Grason-Stadler constant-current generator (Model E1064GS). Shock duration was $0.5 \mathrm{sec}$, and its intensity was adjusted to a level $(.4-.7 \mathrm{~mA})$ which produced a jump but no vocalization. Positive reinforcers employed during initial training and on all subsequent VI 60 -sec schedules were $45 \cdot \mathrm{mg}$ Noyes food pellets. All events were automatically programmed and recorded.

Training commenced with autoshaping to a CRF schedule and proceeded to a VI 60 -sec schedule for 3 or 4 days for $2 \mathrm{~h} /$ day. Additional VI $60-$ sec training $(2-3 \mathrm{~h})$ was conducted on the immediately following 2 or 3 days in the Grason-Stadler chamber with the left bar covered and houselight on.

The Ss were nonsystematically assigned to one of three experimental groups for CER training. Groups 1, 2, and 3 received Schedules $A$ and $B, A 2$ and $B 2$, and $A 3$ and $B 3$, respectively. If a light was used as the $C S$ in Schedule A, then a tone was the CS in Schedule B, and vice versa, for all Ss. Modality of CS with schedule was completely counterbalanced except for Group 1, in which unequal $N$ precluded this. For Group 1, Schedule A1 consisted of five presentations of a $20-\sec \mathrm{CS}(\mathrm{L}$ or $\mathrm{N})$, two of these followed by shock; an additional 11 shocks were administered randomly during the time-out (TO) period. The counterpart schedule (B1) consisted of $10 \quad 10-\mathrm{sec}$ CSs ( $N$ or L), 4 followed by shock, and an additional 9 shocks during TO. Thus, in the two schedules, $A 1$ and B1, the probability of signaled shock was the same, total CS duration was the same, but shocks per total CS duration was doubled in $B 1$, and the contingency between $\mathrm{CS}$ and shock was greater in B1. [Contingency is defined here as the probability of CS and shock divided by the number of shocks occurring in non-CS (TO) periods.] Overall shock density was constant (cf. Table 1). For Group 2, Schedule A2 had 5 20-sec CSs (L or $\mathrm{N})$, of which 4 were followed by shock, and an additional 14 shocks during TO. Schedule B2 had 10 10-sec CSs ( $\mathrm{N}$ or $\mathrm{L}), 4$ followed by shock, and an additional 6 shocks during $\mathrm{TO}$. Thus, in Group 2, probability of signaled shock was greater under A2 than under B2 (.8 vs .4), while shocks per total CS duration were held constant. The contingency between CS and shock is approximately the same under both schedules, whereas overall shock density is greater under A2. In Group 3, Schedule A3 contained 10 
Table 1

\begin{tabular}{|c|c|c|c|c|c|c|c|c|c|c|c|}
\hline Group & $\begin{array}{c}\text { Number } \\
\text { of Ss }\end{array}$ & Schedule & $\begin{array}{c}\text { Number } \\
\text { of CS } \\
\text { Presen- } \\
\text { tations }\end{array}$ & $\begin{array}{c}\text { CS } \\
\text { Dura- } \\
\text { tion } \\
\text { (Sec) }\end{array}$ & $\begin{array}{l}\text { Number } \\
\text { of CSs } \\
\text { Followed! } \\
\text { by Shock: }\end{array}$ & $\begin{array}{c}\text { Shooks } \\
\text { in } \\
\text { Time } \\
\text { Out }\end{array}$ & $\begin{array}{c}\text { Total } \\
\text { Number } \\
\text { of } \\
\text { Shocks }\end{array}$ & $\begin{array}{c}\text { Shock } \\
\text { Density }\end{array}$ & $\begin{array}{l}\text { Shocks/Total } \\
\text { CS Duration }\end{array}$ & $\begin{array}{c}\text { Probability } \\
\text { of } \\
\text { Signaled } \\
\text { Shock }\end{array}$ & Contingency \\
\hline 1 & 9 & $\begin{array}{l}\text { A1 } \\
\text { B1 }\end{array}$ & $\begin{array}{r}5 \\
10\end{array}$ & $\begin{array}{l}20 \\
10\end{array}$ & $\begin{array}{l}2 \\
4\end{array}$ & $\begin{array}{r}11 \\
9\end{array}$ & $\begin{array}{l}13 \\
13\end{array}$ & $\mathbf{A} 1=\mathbf{B} 1$ & $\mathrm{~B} 1>\mathrm{A} 1$ & $\mathrm{~A} 1=\mathrm{B} 1$ & $\mathbf{B 1}>\mathbf{A 1}$ \\
\hline 2 & 12 & $\begin{array}{l}\text { A2 } \\
\text { B2 }\end{array}$ & $\begin{array}{r}5 \\
10\end{array}$ & $\begin{array}{l}20 \\
10\end{array}$ & $\begin{array}{l}4 \\
4\end{array}$ & $\begin{array}{r}14 \\
6\end{array}$ & $\begin{array}{l}18 \\
10\end{array}$ & $A 2>B 2$ & $A 2=B 2$ & $\mathrm{~A} 2>\mathrm{B} 2$ & $A 2=B 2$ \\
\hline 3 & 8 & $\begin{array}{l}\text { A3 } \\
\text { B3 }\end{array}$ & $\begin{array}{l}10 \\
10\end{array}$ & $\begin{array}{l}10 \\
10\end{array}$ & $\begin{array}{l}8 \\
4\end{array}$ & $\begin{array}{l}5 \\
9\end{array}$ & $\begin{array}{l}13 \\
13\end{array}$ & $\mathbf{A} \mathbf{3}=\mathbf{B} 3$ & $A 3>B 3$ & $A 3>B 3$ & A $3>$ B3 \\
\hline
\end{tabular}

10-sec CSs (L or N), 8 followed by shock, and an additional 5 shocks during TO; Schedule B3 had 10 10-sec CSs (N or L), 4 followed by shock, and 9 shocks during TO. Thus, in Group 3, probability of signaled shock is greater under A3 than under B3 (.8 vs .4); also, shocks per total CS duration and contingency are greater under A3 than under B3, while overall shock density is equal for both.

All schedules were $330 \mathrm{sec}$ in duration, during which time the houselight was off. The TO periods which separated CS presentations were varied within and between schedules. Shocks during TO periods were never delivered less than $10 \mathrm{sec}$ before the onset of a CS or less than $15 \mathrm{sec}$ following the termination of a CS.

On the day following completion of CRF and VI 60-sec training, both bars in the chamber were covered and CER conditioning commenced. Each S received the $A$ and $B$ schedule appropriate to its group twice each day for 3 consecutive days. The daily session lasted approximately $40 \mathrm{~min}$. All six possible orders of schedule presentation were employed. Each S received a different order on each of the 3 days of schedule presentation; the orders were varied as completely as possible between Ss on any single day. The $\mathrm{S}$ was removed from the chamber immediately upon termination of the final CS or CS + shock presentation in a given schedule and placed in a holding cage (visually isolated from the experimental chamber) for $5 \mathrm{~min}$. The $\mathbf{S}$ was then again placed in the chamber, and the next schedule begun.

Measurement of suppression to each CS was conducted on the day following the final CER session. During these test periods, the houselight was on, the right side bar uncovered, and a VI 60-sec reinforcement schedule was in effect. During the test session, which lasted approximately $65 \mathrm{~min}$, the $S$ received three presentations of each CS on a VI 500 -sec schedule. The order of the six CS test presentations was determined for each $\mathrm{S}$ according to a Gellerman series, with the restriction that not more than two presentations of the same CS occur consecutively. Each CS $(L$ or $N$ ) was either 50 or $100 \mathrm{sec}$ in duration, depending on which $\mathrm{CS}$ had been the short $(10 \mathrm{sec})$ or long (20 sec), respectively, during training. Thus relative durations of $C S$ in training and testing remained constant. Suppression was measured by the $A / A+B$ ratio, in which $A$ is the number of presses during the first 20 sec of the CS and B is the number of presses in the $200 \mathrm{sec}$ prior to the CS divided by 10 . Thus no suppression is .50 and total suppression is .00 .

\section{RESULTS}

The mean suppression ratios to each of the CSs for all three groups are shown in Table 2. A 3 by 2 by 3 nested mixed design analysis of variance was performed on the suppression ratios. The three levels of the first factor represent the three different groups; the remaining two factors are within-Ss factors representing the two schedules ( $A$ and B) and the three tests appropriate to each CS, respectively. The third factor was significant $(F=15.55, \mathrm{df}=2 / 52$, $\mathrm{p}<.01$ ), indicating extinction of the suppression effect across repeated presentations within the test session. The second factor was significant $(F=6.59, \quad \mathrm{df}=1 / 26, \quad \mathrm{p}<.05)$ indicating that overall the $C S$ in Schedule A was less suppressive than the CS in Schedule B. However, the Schedule by Group interaction was also significant $(\mathrm{F}=5.18, \mathrm{df}=2 / 26$, $\mathrm{p}<.05)$. This interaction can be observed in Table 2. Subsequent tests indicated that Group 1 exhibited

Table 2

Mean Suppression Ratios to the First $20 \mathrm{Sec}$ of the CS in Schedules $A$ and $B$ for Groups 1, 2, and 3 , and $M$ ean Baseline Rate of Response for the $200 \mathrm{Sec}$ Prior to CS Test Periods

\begin{tabular}{|c|c|c|c|c|}
\hline \multirow[b]{2}{*}{ Group } & \multicolumn{2}{|c|}{ CS/Schedule A } & \multicolumn{2}{|c|}{ CS/Schedule B } \\
\hline & $\begin{array}{l}\text { Base- } \\
\text { line }\end{array}$ & $\begin{array}{l}\text { Suppres- } \\
\text { sion }\end{array}$ & $\begin{array}{l}\text { Base- } \\
\text { line }\end{array}$ & $\begin{array}{l}\text { Suppres- } \\
\text { sion }\end{array}$ \\
\hline 1 & 44.48 & .455 & 41 & .29 \\
\hline 2 & 50.44 & .417 & 53.36 & .399 \\
\hline 3 & 41.66 & .371 & 47.12 & .374 \\
\hline
\end{tabular}

significantly less suppression to the CS in Schedule A1 than to the CS in Schedule B1 $(t=3.37, d f=26$, $\mathrm{p}<.01)$. No other within-group differences were significant. The mean baseline rate of response per 200-sec period prior to CS presentation is also presented in Table 2. There was no significant difference among the three groups in their baseline rate of responding $(F<1$, df $=2 / 26)$.

\section{DISCUSSION}

In Group 1 , two factors distinguish Schedule A from Schedule B. Both the number of shocks per total CS duration and the contingency between CS and shock are greater for Schedule B1 than for Schedule A1. Thus, at least one of these factors is implicated in determining suppression. However, both of these factors are present in Group 3, yet there is no significant difference in the amounts of suppression to the respective CSs. This can be accounted for by noting that the CS in Schedule $A$ also has a higher probability of signaling shock. Lockard (1963) has demonstrated that rats prefer signaled shock, and this preference might be indicated by lesser suppression; i.e., preparatory responses which reduce the aversiveness of the shock are more apt to be conditioned under a CS with greater signal value. The failure to find a probability of signaled shock effect in Group 2 may indicate a trading relationship between duration of the signal and the probability with which it signals shock; i.e., the longer the CS, the less likely that preparatory responses will be appropriately timed to offset the consequences of the shock. Similar interpretations have been offered in delay of punishment effects (Knapp, Kause, \& Perkins, 1959). Additional research is needed to separate the factors of duration and probability while holding the other factors (contingency, density, etc.) constant.

\section{REFERENCES}

ANGER, D. 000000000000000000000 000000000 . Unpublished manuscript. Western Michigan State University, 1969. 
BOLLES, R. C., \& GROSSEN, N, E Function of the $C S$ in shuttle-box avoidance learning by rats. Journal of Comparative \& Physiological Psychology, $1970,70,165-169$.

BOLLES, R. C.. STOKES, L. W., \& YOUNGER, M. S. Does CS termination reinforce avoidance behavior? Journal of Comparative \& Physiological Psychology, $1966,62,201-207$

FLEMING, R. A., \& HERSHMAN, R. L The application of information theory to differential conditioning. Paper presented at the meeting of the Psychonomic Society, St. Louis, 1969.
HERRNSTEIN, R.J. Method and theory in the study of avoidance. Psychological Review, 1969, 76, 49-69.

KNAPP, R. K.. KAUSE, R. H., \& PERKINS C. C., JR. Immediate vs delayed shock in T-maze performanee. Journal of Experimental Psychology, 1959, 58 . Experim

LOCKARD, J. S. Choice of a warning signal or no warning signal in an unavoidable shock situation. Journal of Comparative \& Physiological Psychology, 1963,56. $526-530$.

RESCORLA, R. A. Probability of shock in the presence and absence of $C S$ in fear conditioning. Journal of Comparative \& Physiological Psychology, 1968, 66, 1-5.

\section{Preference for mirror image stimulation in goldfish (Carassius auratus)}

\author{
GORDON G. GALLUP, JR., and JOHN Y. HESS \\ Tulane University, New Orleans, La. 70118
}

Ten goldfish, given a continuous choice between orienting toward a mirror or another conspecific behind Plexiglas, exhibited a distinct preference for mirror-image stimulation. Moreover, the ratio of time spent in association with the mirror plus a target fish to time in the neutral zone showed a tendency to increase as a function of the amount of social deprivation imposed prior to testing. The results were discussed in terms of implications for theories that attribute the appetitive properties of mirror confrontation to the fact that it elicits an aggressive display.

It has been demonstrated repeatedly for a number of animals that visual access to a mirror, or what is called mirror-image stimulation (MIS), can serve as a reinforcement for learning to make a variety of instrumental responses (e.g., MacLean, 1964; Thompson \& Sturm, 1965). More recently, evidence has been obtained which shows that at least for some species of fish, birds, and primates, there is a preference for watching their own reflections in mirrors over watching a conspecific behind glass (Baenninger, 1966; Gallup \& Capper, 1970; Gallup \& McClure, 1971). Although many animals respond socially to mirrors, as if the reflection represented another animal (Gallup, 1968), a preference for the reflection implies that MIS represents an atypical form of social stimulation and may impose limitations on the use of mirrors in animal social experimentation.

The present study represents an attempt to assess possible preferences for MIS in goldfish. Furthermore, it has been suggested (e.g., Hogan, 1967) that the appetitive properties of MIS derive primarily from the fact that such stimulation typically elicits an aggressive display. Since goldfish do not ordinarily show stereotyped aggressive displays in response to seeing their reflections, a preference for mirrors would have to be attributable to something other than aggressive motivation.

\section{SUBJECTS}

The Ss consisted of 10 experimentally naive goldfish (Carassius auratus) obtained from a local supplier; they ranged from approximately 5 to $8 \mathrm{~cm}$ in length at the beginning of the experiment. During the course of the experiment, all Ss were maintained on tubifex worms. As far as could be determined, none of the fish had ever been previously exposed to fabricated mirrors.

\section{APPARATUS}

The apparatus consisted of a 10-gal aquarium fitted with Plexiglas partitions which provided for a $.12-\mathrm{m}$-wide $\times .51-\mathrm{m}$-long underwater alley. On the outside of the last $.12 \mathrm{~m}$ of one $.51-\mathrm{m}$ wall was a $.12 \times .12 \mathrm{~m}$ glass mirror. Attached to the outside of the same wall at the other end of the alley was a $.12-\mathrm{m}$-square Plexiglas container for temporarily housing a target or stimulus fish. By placing the stimuli on the outside of the last $.12 \mathrm{~m}$ of either end of one wall, rather than at opposing ends of the alley, a fish would not be able to view both stimuli simultaneously from any position in the alley. In addition, the alley was constructed such that the position of the mirror and target fish container could be reversed as a control for position preferences.

Except for the last $.12 \mathrm{~m}$ of either end of the wall separating the alley from the mirror and stimulus fish container, the inside of the entire alley was painted white in an attempt to eliminate extraneous extraalley cues. The alley and the target container were filled with dechlorinated tap water to a height of $.11 \mathrm{~m}$, and water temperature during testing was maintained at approximately $74^{\circ} \mathrm{F}$.

Electric timers activated by single-throw switches were used to record the amount of time spent by a fish in different portions of the alley. PROCEDURE

The Ss were divided randomly into two groups of five fish and were housed in separate aquaria. After adaptation to the housing conditions, each group was then placed into the alley for 3 days to adapt them to the experimental situation. Both the mirror and a stimulus fish in the Plexiglas container were present during the adaptation period.

Preference testing was initiated by placing an individual fish in the alley for $60 \mathrm{~min}$. Three 10-min observations were made after the first 10,30 , and $50 \mathrm{~min}$ of the 1 -h period, during which time the number of seconds spent in front of the mirror and in front of the target fish were recorded.

The second phase of the experiment represented a preliminary attempt to assess the effect of social-deprivation on visual preferences. Seven days after all Ss had been tested according to the above regime, half of the fish were isolated from each other in opaque individual containers for $30 \mathrm{~min}$ before receiving an additional $60-\mathrm{min}$ trial. The remaining five fish were isolated for $120 \mathrm{~min}$ prior to receiving a second trial.

\section{RESULTS}

The average amount of time spent in front of the mirror, the target fish, and in the neutral portion of the alley was summed over the three $10-\mathrm{min}$ recording periods and is depicted in Fig. 1. As can be seen, the fish spent roughly three times more time in front of the mirror than in front of the target fish. The difference between time spent in the mirror zone vs the target fish area was analyzed by computing a $t$ test for related measures and proved to be statistically significant $(t=4.33, \mathrm{df}=9, \mathrm{p}<.01)$. As a further check on these differences, a sign test run on the same comparison also yielded evidence of a 